\title{
SINTESIS O-KARBOKSIMETIL KITOSAN PADA BERBAGAI KONSENTRASI NaOH DAN SUHU REAKSI SERTA APLIKASINYA SEBAGAI ANTIBAKTERI
}

\section{[Synthesis of O-Carboxymethyl Chitosan in Various of NaOH Concentrations and The Reaction Temperature and Applied as Antibacterial]}

\author{
Jaya Hardi ${ }^{{ }^{\star}}$, Nurakhirawati ${ }^{1}$, Ahmad Ridhay ${ }^{1}$, Musdalifah ${ }^{1}$ \\ 1) Jurusan Kimia Fakultas Matematika dan IImu Pengetahuan Alam Universitas Tadulako \\ J. Soekarno Hatta, Kampus Bumi Tadulako Tondo Palu, Telp. 0451- 422611
}

Diterima 14 Desember 2016, Disetujui 28 Januari 2017

\begin{abstract}
The research about the influence of $\mathrm{NaOH}$ concentrations and reaction temperature to $\mathrm{O}$ Carboxymethyl Chitosan (O-CMC) synthesis and it is antibacterial application was done. This research intent on detect $\mathrm{NaOH}$ concentration and reaction temperature that resulting of $\mathrm{O}-\mathrm{CMC}$ with highest of yield, solubility, and substitution degrees, and also to find out FTIR spectrum and antibacterial activity of O-CMC. The produce of O-CMC was done by using a Completely Randomized Design (CRD) with the variation of $\mathrm{NaOH}$ concentration of $20 \%, 30 \%, 40 \%, 50 \%$, and $60 \%$, and also reaction temperature of 20,30 , and $40 \mathrm{oC}$. The result was showed that on the $\mathrm{NaOH}$ concentration of $60 \%(\mathrm{w} / \mathrm{v})$ and temperature of $30 \mathrm{oC}$ was resulted highest of yield, solubility, and substitution degrees of $41.5 \%, 31 \mathrm{~g} / \mathrm{L}$, and 0.67 , respectively. FTIR spectrum was showed that bending vibration of primary amine $(-\mathrm{NH} 2)$ give two bands for O-CMC. The broadest inhibition area of O-CMC $(1.43 \mathrm{~cm})$ was showed on Salmonella sp.
\end{abstract}

Keywords: chitosan, O-CMC, substitution degree, antibacterial

\begin{abstract}
ABSTRAK
Telah dilakukan penelitian tentang pengaruh konsentrasi $\mathrm{NaOH}$ dan suhu terhadap proses sintesis $\mathrm{O}$ karboksimetil kitosan (O-KMK) dan aplikasinya sebagai antibakteri. Penelitian ini bertujuan untuk mengetahui konsentrasi $\mathrm{NaOH}$ dan suhu reaksi yang dapat menghasilkan O-KMK dengan rendemen, kelarutan, dan derajat substitusi tertinggi, dan pola spektrum FTIR O-KMK, serta untuk mengetahui daya hambat antibakteri dari O-KMK yang dihasilkan. Pembuatan O-KMK dilakukan dengan menggunakan Rancangan Acak Lengkap (RAL) dengan variasi konsentrasi $\mathrm{NaOH} 20,30,40,50$, dan $60 \%$ dan suhu reaksi 20,30 dan $40^{\circ} \mathrm{C}$. Hasil penelitian menunjukkan bahwa pada konsentrasi $\mathrm{NaOH}$ $60 \%(\mathrm{~b} / \mathrm{v})$ dan suhu $30^{\circ} \mathrm{C}$ menghasilkan rendemen, kelarutan, dan DS tertinggi, masing $41,5 \% ; 31$ $\mathrm{g} / \mathrm{L} ; 0,67$. Spektrum FTIR menunjukkan terbentuknya sepasang pita serapan vibrasi tekuk -NH2 primer atau terbentuk O-KMK. O-KMK hasil sintesis menghasilkan daya hambat tertinggi pada bakteri Salmonella sp. $(1,43 \mathrm{~cm})$.
\end{abstract}

Kata kunci: kitosan, O-KMK, derajat subtitusi, antibakteri 


\section{LATAR BELAKANG}

Kitosan atau poli-(2-amino-deoksi- $\beta$ (1-4)-D-glukopiranosa merupakan turunan dari kitin melalui proses deasetilasi dengan menggunakan basa kuat pada temperatur yang cukup tinggi (Kurita, 2006). Kitosan memiliki fungsi yang banyak, akan tetapi kelarutan kitosan yang rendah dalam air membatasi pemanfaatannya. Oleh karena itu, banyak dilakukan modifikasi struktur kimia kitosan untuk meningkatkan kelarutannya. Salah satu modifikasi tersebut adalah karboksimetil kitosan. Chen et al., (2003) memodifikasi kitosan dengan asam kloro asetat pada suhu rendah untuk mendapat produk yang larut air berupa senyawa Okarboksimetil kitosan.

Karboksimetil kitosan (KMK) merupakan produk hasil sintesis yang diperoleh dengan cara substitusi gugus karboksimetil pada rantai glukosamin pada struktur kitosan. Senyawa ini memiliki kelarutan yang lebih tinggi dalam air daripada kitosan akibat pertambahan muatan ionik. Penelitian Patale \& Patravale (2011) menunjukkan selain memperbaiki kelarutan kitosan, karboksilasi juga mampu meningkatkan sifat fungsional kitosan. Karboksimetil kitosan terbagi dalam 4 jenis senyawa yaitu N-, O-, N-O, dan N-N-KMK.

Pembuatan karboksimetil kitosan dipengaruhi oleh beberapa faktor, diantaranya rasio antara kitosan terhadap asam monokloroasetat, kemurnian kitosan, suhu reaksi, dan konsentarsi
$\mathrm{NaOH}$ pada proses alkalisasi (Kurita, 2006). Jumlah alkalis kitosan yang diperoleh (proses alkalinasi) juga berpengaruh dalam pembentukan KMK. Banyaknya jumlah alkali $(\mathrm{NaOH})$ yang ditambahkan pada kitosan dalam proses alkalinasi mempengaruhi jumlah ion $\mathrm{Na}^{+}$ yang diikat oleh kitosan. Basmal dkk., (2005) melaporkan bahwa alkalinasi menggunakan $\mathrm{NaOH} 50 \%$ pada berbagai perlakuan konsentrasi asam monokloroasetat menghasilkan Okarboksimetil kitosan dengan tingkat kelarutan dalam air sebesar 9,85 $\mathrm{ml} / 1 \mathrm{~g}$ KMK, sedangkan penelitian berikutnya oleh Basmal dkk., (2007) menggunakan $\mathrm{NaOH} 5 \%$ menghasilkan NO-karboksimetil kitosan (NO-KMK) dengan jumlah kitosan yang terlarut dalam air sebesar 5,37\%. Sementar itu, Saputra (2014) melaporkan penggunaan $\mathrm{NaOH} 10 \mathrm{M}$ dapat menghasilkan KMK dengan rendemen yang tinggi pada sekitar $\mathrm{pH} 4$.

O-KMK biasanya dapat disintesis pada rasio kitosan terhadap asam (1:4) dan pada suhu yang rendah, yaitu $0-30^{\circ} \mathrm{C}$. Sementara suhu $30^{\circ} \mathrm{C}$ hingga $60^{\circ} \mathrm{C}$ dapat menghasilkan campuran N-O-KMK dan OKMK. Sementara itu, konsentrasi kitosan yang sering digunakan adalah $4-20 \%$ (b/v) dalam $40-50 \%(b / v)$ larutan $\mathrm{NaOH}$. Pada proses eterifikasi, konsentrasi asam monokloroasetat yang biasa digunakan adalah $1: 1, \quad 1: 4$, dan $1: 6$ dalam isopropanol/etanol (b/v). Sementara itu, OKMK memiliki sifat antibakteri yang lebih tinggi daripada kitosan dan N-O-KMK, 
sehingga O-KMK memiliki potensi yang sangat besar pada peningkatan nilai ekonomis turunan kitosan (Mourya et al., 2010).

Belum dilakukannya kajian tentang penggunaan berbagai variasi $\mathrm{NaOH}$ yang selanjutnya dihubungkan dengan suhu reaksi terhadap mutu O-KMK hasil sintesis, sehingga perlu adanya penelitian lanjut ke arah tersebut dan selanjutnya digunakan untuk mengkaji aktivitas antibakteri dari senyawa O-KMK.

\section{METODE PENELITIAN}

\section{Bahan dan Peralatan}

Alat yang diperlukan dalam penelitian ini adalah oven, desikator, magnetik stirrer, neraca analitik, blender, homogenizer, water bath, sentrifugasi, laminar flow, $\mathrm{pH}$ meter, Spektrofotometer Fourier Transform Infra Red (FTIR) ATR alpha Bruker, dan alat-alat gelas yang umum di laboratorium kimia.

Bahan dalam penelitian ini adalah kitosan, $\mathrm{NaOH}$, natrium monokloroasetat, asam asetat glasial, methanol $70 \%$, Isopropil alkohol, bakteri Staphylococcus aureus, E. coly, dan Salmonela sp., aquades, indikator metil merah, $\mathrm{HCl} 0,13$ $\mathrm{M}, \mathrm{NaCl}$ fisiologis, media NA, kapas.

\section{Prosedur Penelitian}

Penelitian dilakukan dengan menggunakan rancangan acak lengkap dengan dua faktor yaitu konsentrasi $\mathrm{NaOH}$ $(20,30,40,50$, dan 60\%) dan suhu sintesis $\left(20,30\right.$, dan $\left.40^{\circ} \mathrm{C}\right)$.

\section{Sintesis O-Karboksimetil Kitosan}

Senyawa O-KMK disintesis dengan menggunakan metode Chen et al. (2003) dengan beberapa modifikasi. 2 gram kitosan ditambah $50 \mathrm{~mL}$ isopropil alkohol dan dikocok menggunakan magnetik stirer pada suhu ruang selama 2 jam. Suspensi yang terbentuk selanjutnya ditambahkan $40 \mathrm{~mL} \mathrm{NaOH}$ dengan konsentrasi sesuai perlakuan. Campuran diaduk dengan magnetik stirrer selama 2 jam pada temperatur ruang, kemudian 8 gram asam monokloro asetat di dalam $24 \mathrm{~mL}$ isopropil alkohol ditambahkan tetes demi tetes kedalam campuran. Campuran selanjutnya dihomogenizer selama 2 jam pada suhu sesuai perlakuan. Hasil homogenizer kemudian dinetralkan dengan asam asetat glasial, setelah itu campuran hasil penetralan disaring. Endapan yang terbentuk dicuci dengan metanol $70 \%$ dengan perbandingan 1:15, endapan kembali disaring dan selanjutnya dikeringkan dalam oven suhu $60^{\circ} \mathrm{C}$ semalaman. Padatan kering selanjutnya digiling untuk mendapatkan serbuk OKMK. Serbuk O-KMK ditentukan rendemen, kelarutan, derajat subsitusi dan pola spektrum FTIR. O-KMK dengan hasil terbaik selanjutnya diuji aktivitas anibakterinya.

Uji Aktivtas Antibakteri (Nurainy et al., 2008)

Pengujian ini menggunakan metode sumur difusi dengan cara suspensi bakteri uji yang telah disiapkan dioleskan merata pada media Nutrien Agar, selanjutnya 
dibuat empat sumur/ lubang. Dua sumur ditetesi pelarut sebagai kontrol negatif, sedangkan dua sumur lainnya ditetesi masing-masing dengan O-KMK dan kitosan dengan konsentrasi 5\%. Media uji selanjutnya diinkubasi selama 24 jam pada suhu $37^{\circ} \mathrm{C}$. Area yang jernih pada disekitar sumur diukur diameternya sebagai area zona hambatan bakteri.

\section{HASIL DAN PEMBAHASAN}

\section{O-KMK Hasil Sintesis Pada Berbagai Konsentrasi $\mathrm{NaOH}$}

Hasil sintesis menunjukkan bahwa rendemen O-KMK meningkat seiring dengan peningkatan konsentrasi $\mathrm{NaOH}$ (Gambar 1). Peningkatan rendemen OKMK disebabkan karena pada penggunaan konsentrasi $\mathrm{NaOH}$ yang semakin tinggi, maka semakin banyak pula kitosan alkali yang terbentuk sehingga meningkatkan kemampuan kitosan untuk berikatan dengan gugus karboksimetil. Rendemen $\mathrm{O}$ KMK tertinggi diperoleh penggunaan $\mathrm{NaOH}$ $60 \%$, yaitu $43,75 \%$.

Kualitas O-KMK yang dihasilkan dapat ditinjau pada kelarutannya dalam air. Adanya substitusi gugus karboksimetil dari asam monokloroasetat pada kitosan maka terdapat gugus polar tambahan dalam molekul yang menyebabkan OKMK dapat larut dalam air. Analisis kelarutan untuk pengaruh konsentrasi $\mathrm{NaOH}$ menunjukkan bahwa kelarutan karboksimetil kitosan berkisar antara 14 hingga 30,5 g/L (Gambar 2). Seperti halnya rendemen, kelarutan O-KMK juga meningkat seiring dengan meningkatnya konsentrasi $\mathrm{NaOH}$. Hal ini tidak lepas dari semakin banyaknya $\mathrm{NaOH}$ tentu akan mengaktifkan gugus -OH semakin banyak, sehingga kemampuan untuk berikatan dengan karbokation $\left({ }^{+} \mathrm{CH}_{2} \mathrm{COOCl}\right)$ akan tinggi. Banyaknya gugus $\mathrm{CH}_{2} \mathrm{COO}^{-}$yang terikat pada kitosan tentunya akan meningkatkan kepolaran dan meningkatkan pula kelarutannya.

Derajat subtitusi merupakan parameter selanjutnya yang harus dikaji pada sintesis O-KMK. Nilai derajat substitusi tertinggi pada O-KMK hasil sintesis diperoleh pada penggunaan $\mathrm{NaOH} 60 \%$, yaitu 0,66 (Gambar 3). Penggunaan $\mathrm{NaOH}$ dengan konsentrasi yang semakin tinggi akan meningkatkan jumlah ion $\mathrm{Na}^{+}$yang selanjutnya bereaksi dengan kitosan membentuk kitosan alkali. Oleh karena itu, pada saat penambahan natrium monokloroasetat akan terjadi pertukaran ion, yakni ion $\mathrm{Na}^{+}$yang mudah larut dalam air akan terikat dengan ion $\mathrm{Cl}^{-}$ dari monokloroasetat dan membentuk garam $\mathrm{NaCl}$. Kitosan yang telah melepaskan ion $\mathrm{Na}^{+}$akan bersifat reaktif terhadap gugus karboksil dari monokloroasetat sehingga membentuk KMK (Rahmawati dan Iskandar, 2014).

Hasil analisis spektrum FTIR senya O-KMK (Gambar 4) menunjukkan bahwa pada bilangan gelombang sekitar 1653 $\mathrm{cm}^{-1}$ dan $1561 \mathrm{~cm}^{-1}$ diasumsikan sebagai pasangan serapan vibrasi tekuk untuk gugus $\mathrm{N}-\mathrm{H}$ primer sebagai ciri bahwa subtitusi sebagian besar terjadi pada gugus $-\mathrm{OH}$. 


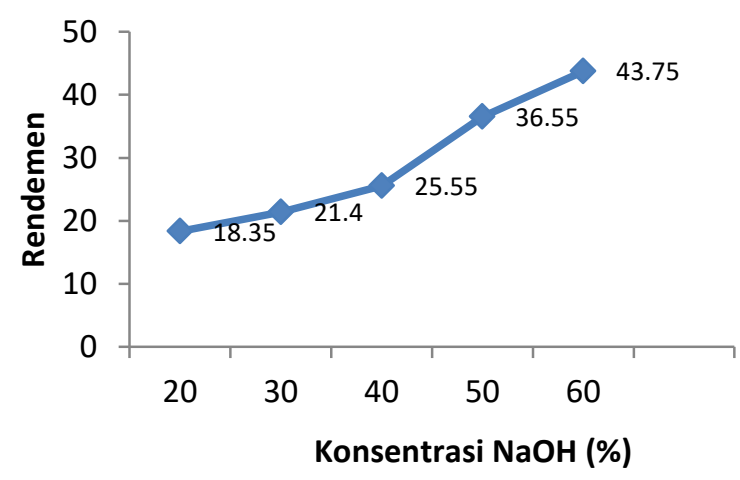

Gambar 1. Rendemen O-KMK pada berbagai konsentrasi $\mathrm{NaOH}$

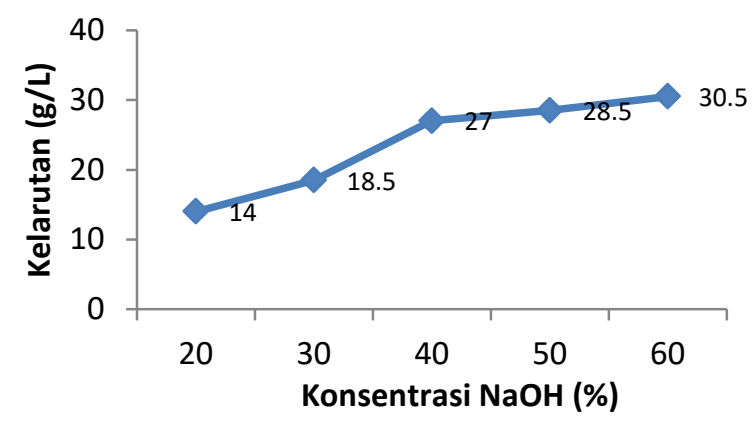

Gambar 2. Kelarutan O-KMK pada berbagai konsentrasi $\mathrm{NaOH}$

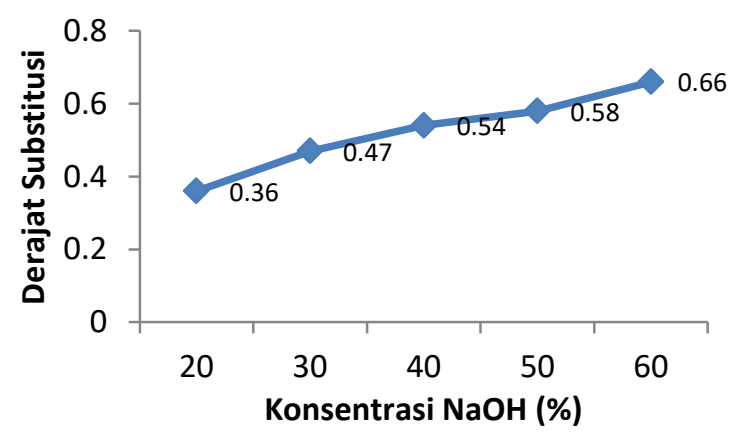

Gambar 3. DS O-KMK pada berbagai konsentrasi $\mathrm{NaOH}$

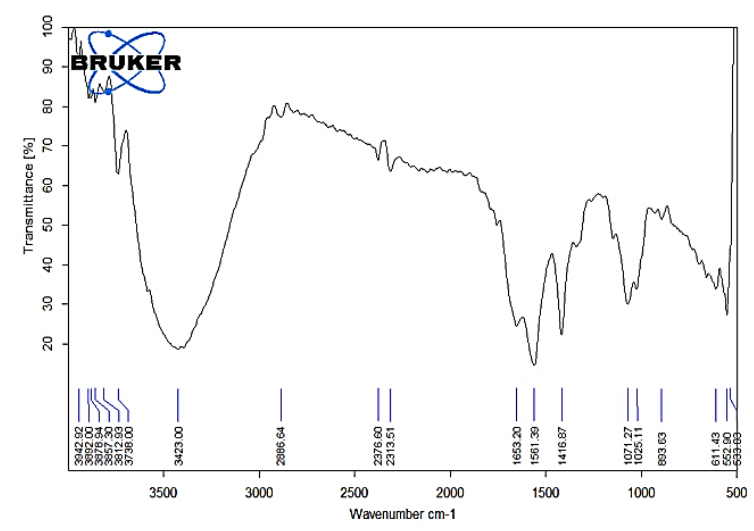

Gambar 4. Hasil analisis FTIR pada penggunaan $\mathrm{NaOH} 60 \%$
O-KMK Hasil Sintesis pada Berbagai Suhu Sintesis.

Perlakuan suhu terhadap rendemen O-KMK yang dihasilkan menunjukkan peningkatan hingga rendemen tertinggi $44,9 \%$ pada suhu $40^{\circ} \mathrm{C}$ (Gambar 5). Akan tetapi, berdasarkan uji statistik diperoleh bahwa rendemen pada suhu $30^{\circ} \mathrm{C}$ dan $40^{\circ} \mathrm{C}$ memiliki perbedaan yang tidak nyata atau dengan kata lain penggunaan suhu $30^{\circ} \mathrm{C}$ lebih efisien. Peningkatan jumlah rendemen disebabkan oleh semakin banyaknya karbo kation yang terbentuk dari natrium monokloro asetat pada saat suhu meningkat. Dengan demikian, reaksi eterifikasi semakin berjalan efektif atau substitusi gugus $-\mathrm{CH}_{2} \mathrm{COO}^{-}$semakin banyak.

Penggunaa suhu sintesis yang tinggi pada reaksi eterifikasi cenderung tidak mempengaruhi kelarutan O-KMK (Gambar 6). Sintesis O-KMK pada suhu $30^{\circ} \mathrm{C}$ dan $40^{\circ} \mathrm{C}$ menghasilkan kelarutan yang paling tinggi, yaitu $31 \mathrm{~g} / \mathrm{L}$. Akan tetapi penggunaan suhu di atas $30^{\circ} \mathrm{C}$ tidak dianjurkan pada sintesis O-KMK, karena subtitusi dapat terjadi pada gugus amina kitosan (Mourya et.al., 2010). Rahmawati dan Iskandar (2014) melaporkan kelarutan $\mathrm{KMK}$ pada suhu $60^{\circ} \mathrm{C}$ adalah $27,7 \mathrm{~g} / \mathrm{L}$.

Derajat substitusi yang diperoleh pada perlakuan suhu berkisar antara 0,48 hingga 0,7 dengan nilai tertinggi pada perlakuan suhu $40^{\circ} \mathrm{C}$ (Gambar 7), akan tetapi secara statistik (uji ANOVA) berbeda tidak nyata dengan suhu $30^{\circ} \mathrm{C}$ $(0,67)$. Mouriya et al., (2010) 
mengemukakan bahwa KMK dengan DS $\pm 0,82$ umumnya dalam bentuk O-KMK yang tersubtitusi pada posisi C6, sedangkan DS $\pm 0,65$ membentuk O-KMK yang tersubtitusi pada posisi C3 dan C6, serta untuk DS $\pm 0,5$ umumnya membentuk N-KMK atau subtitusi terjadi pada posisi amina. Berdasarkan data yang diperoleh, maka penggunaan suhu $30^{\circ} \mathrm{C}$ dan $40^{\circ} \mathrm{C}$ diasumsikan bahwa menghasilkan O-KMK yang tersubtitusi pada posisi C3 dan C6.

Hasil penelitian menunjukkan bahwa spektrum FTIR karboksimetil kitosan yang disintesis dengan perlakuan suhu $20-40^{\circ} \mathrm{C}$ menunjukkan terbentuknya gugus karboksimetil pada senyawa kitosan (Gambar 8). Terlihat bahwa vibrasi ulur gugus $-\mathrm{OH}$ untuk terserap pada bilangan gelombang $3410 \mathrm{~cm}^{-1}$. Pada bilangan gelombang $2977 \mathrm{~cm}^{-1}$ dan $2938 \mathrm{~cm}^{-1}$ merupakan serapan gugus fungsi $-\mathrm{C}-\mathrm{H}$. Serapan pada $1649 \mathrm{~cm}^{-1}$ dan $1569 \mathrm{~cm}^{-1}$ diasumsikan sebagai vibrasi tekuk untuk gugus -N-H primer. Mourya et.al., (2010) melaporkan bahwa vibrasi tekuk gugus $\mathrm{NH}^{3+}$ berada pada bilangan gelombang 1624 dan $1506 \mathrm{~cm}^{-1}$.

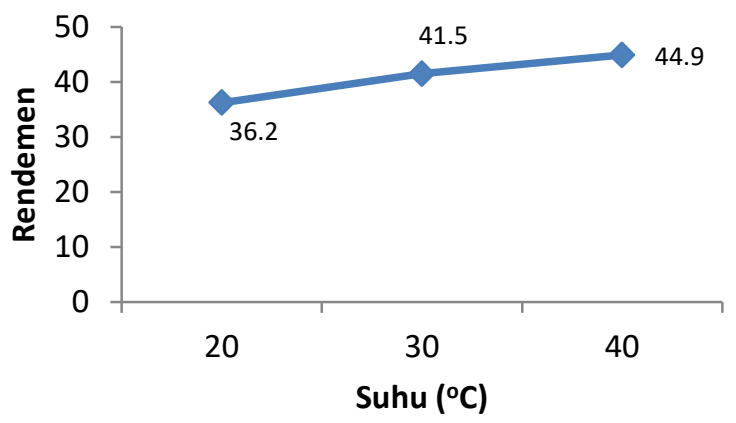

Gambar 5. Rendemen O-KMK pada berbagai suhu

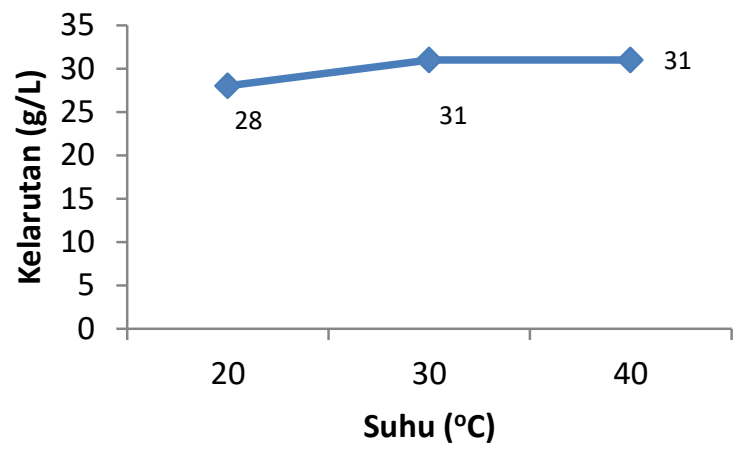

Gambar 6. Kelarutan O-KMK pada berbagai suhu

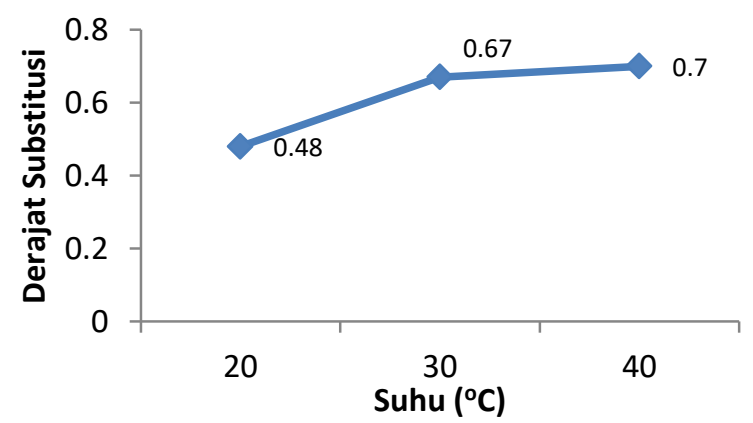

Gambar 7. Derajat substitusi pada berbagai suhu

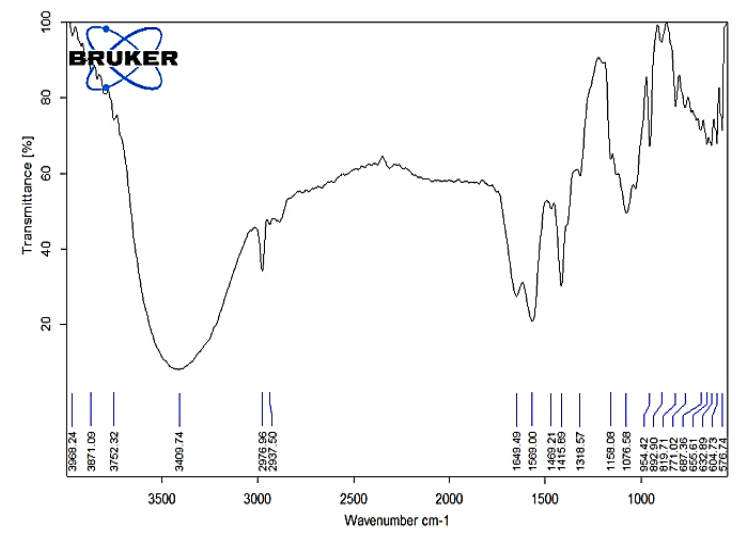

Gambar 8. Hasil analisis FTIR pada suhu $30^{\circ} \mathrm{C}$

\section{Aktivitas Antibakteri O-KMK}

Pengujian daya hambat senyawa $\mathrm{O}-$ KMK hasil sintesis terpilih dilakukan terhadap bakteri Staphylococus aureus (bakteri Gram positif), Escherichia coli (bakteri Gram negatif) dan Salmonella sp. (bakteri Gram negatif). Pengamatan zona hambat terhadap Staphylococcus aureus menunjukkan diameter zona hambat dari 
kitosan sebagai pembanding diperoleh 0,27 cm hampir sama dengan O-KMK hasil sintesis dengan zona hambat 0,24 $\mathrm{cm}$. Pada bakteri Escherichia coli, zona hambat O-KMK yaitu $0,27 \mathrm{~cm}$, sedangkan pada kitosan tidak terdapat zona hambat. Zona hambat bakteri Salmonella sp yang paling besar juga terdapat pada penggunaan $\mathrm{O}-\mathrm{KMK}$, yaitu $1,43 \mathrm{~cm}$ dan pada kitosan hanya $0,40 \mathrm{~cm}$. Data tersebut cukup membuktikan bahwa OKMK lebih efektif sebagai antibakteri dibandingkan dengan kitosan tanpa modifikasi khususnya pada bakteri Gram negatif, yaitu Escherichia coli dan Salmonella $s p$.

Sifat antibakteri dari senyawa OKMK terjadi karena pada O-KMK subtitusi hanya terjadi pada $-\mathrm{OH}$, sedangkan pada $-\mathrm{NH}_{2}$ tidak terjadi perubahan. Oleh karena itu, gugus $-\mathrm{COOH}$ akan mengalami reaksi inter- ataupun intramolekular dengan gugus $-\mathrm{NH}_{2}$ tadi dan menghasilkan gugus $-\mathrm{NH}^{3+}$ yang lebih banyak dibandingkan pada kitosan. Gugus inilah yang nantinya sangat efektif sebagai antibakteri (Mourya et al., 2010).

\section{KESIMPULAN}

Berdasarkan hasil penelitian maka dapat disimpulkan bahwa penggunaan konsentrasi $\mathrm{NaOH}$ dan suhu sintesis terbaik didapatkan pada konsentrasi $60 \%$ dan suhu $30^{\circ} \mathrm{C}$ dengan rendemen $41,5 \%$, kelarutan $31 \mathrm{~g} / \mathrm{L}$, dan DS 0,67. O-KMK menghasilkan bilangan gelombang sekitar $1650 \mathrm{~cm}^{-1}$ dan $1560 \mathrm{~cm}^{-1}$ sebagai serapan vibrasi tekuk untuk gugus $\mathrm{N}-\mathrm{H}$ primer. OKMK memiliki daya hambat yang tinggi pada bakteri Salmonella $s p$. dengan diameter daya hambat $1,43 \mathrm{~cm}$.

Berdasarkan hasil yang diperoleh maka perlu dilakukan penelitian lebih lanjut tentang pengaruh derajat deasetilasi kitosan terhadap sintesis O-KMK.

\section{UCAPAN TERIMAKASIH}

Ucapan terimakasih dihaturkan kepada jajaran pimpinan Faklutas MIPA Universitas Tadulako yang telah memberikan Insentif Penelitian.

\section{DAFTAR PUSTAKA}

Basmal, J., Prasetyo, A., dan Fawzya, Y.N., 2005, Pengaruh Konsentrasi Asam Monokloroasetat dalam proses Karboksimetil Kitosan terhadap Karboksimetil Kitosan yang dihasilkan. J. Penel. Perik, Indonesia. 11(8): 47-58.

Basmal. J., Prasetyo, A., dan Farida, Y. 2007. Pengaruh Suhu Eterifikasi pada Pembuatan Karboksimetil Kitosan. Jurnal Pascapanen dan Bioteknologi Kelautan dan Per-ikanan. 2(2): 99106.

Chen, X.G., and Park, H.J. 2003. Chemical Characteristic of $\mathrm{O}$ Carboxymethyl Chitosan Related to the Preparation Conditions. Carbohydrate Polymer. 53 : 355-359.

Kurita, K. 2006. Chitin and Chitosan: Functional Biopolymers from Marine Crustaceans (Mini Review). Marine Biotechnology. 8:203-226.

Mourya, V.K., Inandar, N.N., Tiwari, A. 2010. Carboxymethyl Chitosan and Its Aplicasions. [Review]. Adv Mat. Left. 1 (1):11-33.

Nurainy F, Rizal S, Yudiantoro. 2008. Pengaruh Konsentrasi Kitosan 
Terhadap Aktivitas Antibakteri dengan Metode Difusi Agar (Sumur). Jurnal Teknologi Industri dan Hasil Pertanian. 13(2): 117-125.

Patale, R.L. \& V.B. Patravale. 2011. O,Ncarboxymethyl chitosan-zinc complex: A novel chitosan complex with enhanced antimicrobial activity. Carbohydrate Polymers. 85: 105-110.
Rahmawati H., Iskandar D. 2014. Sintesis Karboksimetil Kitosan Terhadap Pengaruh Konsentrasi Natrium Hidroksia dan Rasio Kitosan Dengan Asam Monokloro Asetat. Jurnal Teknologi Technoscientia. 6(2): 145155.

Saputra MJA. 2014. Karakterisasi Carboxymethil Chitosan dengan Variasi Konsentrasi $\mathrm{NaOH}$. [Skripsi]. Bogor: Departemen THP IPB. 